\title{
Training Strategy of the International Talents in Chinese Medicine Under the Background of "The Belt and Road"
}

\author{
Xie Qun, Jin Aning \\ (International Education College , Northeast Asia Traditional Chinese Medicine Communication \\ and Dewelopment Center of Changchun University of Chinese Medicine, Lecturer)
}

Keywords: "The Belt and Road", the International Talents in Chinese Medicine, Training Strategy

\begin{abstract}
Traditional Chinese medicine has made great contributions to the development and prosperity of Chinese nation for thousands of years, which is the treasure of the Chinese nation and the essence of Chinese traditional culture. Under the strategy background of the implementation of "The Belt and Road" in our country, with the change of the concept of health and the medical model, Chinese traditional medicine ushered in the unprecedented development opportunity, so cultivating internationalized talents of Chinese medicine is of great significance on promoting the development of Chinese traditional medicine in countries along the The Belt and Road. Therefore, the optimization of personnel training mode, and the cultivation of internationalized talents with solid professional knowledge, proficient basic skills, the international practice and relevant laws and regulations, an international vision and innovation consciousness and the ability of cross-cultural communication to make Chinese traditional medicine to the world stage is the problem we need to solve.
\end{abstract}

\section{Introduction}

Traditional Chinese medicine has made great contributions to the development and prosperity of Chinese nation for thousands of years, which is the treasure of the Chinese nation and the essence of Chinese traditional culture. On November 16, 2010, UNESCO added "acupuncture and moxibustion to the representative list of intangible cultural heritage of mankind. Two ancient Chinese medicine books of "The Inner Canon of Huangdi" and "Compendium of Materia Medica" in 2011 was included in the "Memory of the World Register", it can be said that the culture of traditional Chinese medicine is an important weapon for the soft power of Chinese culture.

"Chinese medicine diplomacy" has a long history. In recent years, the internationalization of Chinese medicine development has received high attentions: Chinese government has promulgated the"medium-term and long-term plans for foreign exchange and cooperation of Chinese medicine (2011-2020)","Certain opinions on the promotion of Chinese medicine service trade development from the Ministry of Commerce and other fourteen ministries "," planning outline for the development strategy of Chinese medicine (2016-2030)" and other important planning documents; When President xi jinping of China met with the director-general of the world health organization, Margaret chan, at the great hall of the people on August 20, 2013, he proposed to promote the integration of Chinese and western medicine and the development of traditional Chinese medicine abroad".In 2015, Premier Li Keqiang explicitly stated in the work report of the government: "to actively develop ethnic medicine and traditional Chinese medicine"; WHO has issued the "who traditional medicine strategy for 2014-2023 year " and so on. This series of measures provides a good opportunity for access and development of Chinese medicine in overseas. At present, Chinese medicine has spread to 171 countries and regions in the world, and there are nearly 10 million Chinese medical institutions overseas, and Chinese medicine practitioners reached 300 thousand people, China signed 83 international diplomacy cooperation agreements in Chinese medicine with foreign governments and relevant international organizations ${ }^{\mathbb{\Phi}}$, receiving extensive attention and recognition of the international community. However, chief expert of Chinese medicine practitioners qualification authentication center of the State Administration of traditional Chinese 
medicine, Beijing University of Chinese Medicine professor Liu Jingyuan pointed out in 2015 annual meeting of the international exchange and cooperation committee of Chinese National Medicine Institute and the first Chinese Medicine International Forum: "international and professional talents in high level of Chinese medicine are deficient, and the level of Chinese Medicine international health service talents is uneven, especially among overseas Chinese medicine employees, "the cook traditional Chinese medicine", "tour guide Chinese medicine" are quite a few. In addition, the development of Chinese medicine education is unbalanced, and the gap between the quality of teaching is large, but also to some extent, which affected the development of international education of Chinese medicine." ${ }^{\odot}$ Visible, Chinese medicine faces many obstacles on the internationalization road.

In February 2017, "Opinions on strengthening and improving the ideological and political work in Colleges and Universities under the new situation" issued by the CPC Central Committee and the State Council, pointed out that colleges and universities shoulder the important mission of talents cultivation, scientific research, social services, cultural heritage, innovation, international exchanges and cooperation. "The Belt and Road" initiative provides a good opportunity for the complementary advantages, multilateral cooperation, joint development of countries along road. Especially the history of medical and health care of countries and regions along "The Belt and Road" with traditional Chinese medicine, provides a new platform for the international cooperation with Chinese medicine. Therefore, Chinese universities should make full use of this opportunity, combined with geographical advantages and the characteristics of the subject itself, with "The Belt and Road" health cooperation demand as the guidance, to cultivate diversification, high-quality of internationalization of Chinese medicine talents, and to convey fresh blood for the international development of traditional Chinese medicine.

First, strengthen the cultivation of international talent consciousness, and create a strong international atmosphere

In the new era of global economic integration development, Chinese medicine colleges and universities should stand in the height of education internationalization, increase the publicity of higher education internationalization, and guide the whole school teachers and students to actively participate in international exchanges and cooperation work. Experts and teachers in Chinese medicine colleges and universities should form an international strategic thinking,with enhancing the competitiveness of traditional Chinese medicine in the international market as the direction, and become the main force of cultivating professional talents with high-quality, strong profession and language by drawing on the experience of Chinese medicine going abroad.

Strengthen the construction of international cooperation and exchanges in the management team effectively, give full play to the bridge and media role of foreign affairs staff; encourage the college and research Institute actively carry out foreign exchange and cooperation according to their own professional and development characteristics, make full use of its teaching and research functions to steadily promote the internationalization work of Chinese Medicine; real time collect resources conducive to the development of international cooperation and exchange achieve mutual and complementary resources, and special emphasis on the advantage of the frontier positions of overseas alumni.

Two, actively carry out teaching reform, and optimize the talent training mode

The exact clinical effect is the source power to improve the service ability of Chinese medicine and to open the overseas market. Therefore, it is an important task for Chinese medical colleges to train excellent talents of traditional Chinese medicine. According to the needs of Chinese medicine into the international market, Chinese colleges should take related knowledge instruction in traditional Chinese medicine and language practice ability training as the basis, improvement of the students' comprehensive ability as the core, service for overseas development of the Chinese medicine as guide, and conduct the reform of curriculum system, innovation of teaching content and increase of teaching methods, in order to cultivate high-quality compound talents with global vision,

\footnotetext{
(1) "Chinese medicine diplomacy: how to go the international route" .Guangming daily.January 4, 2016

(2) "Chinese medicine diplomacy: how to go the international route" .Guangming daily.January 4, 2016
} 
professional knowledge and communication skills.

\section{Reform of curriculum system and innovation of teaching content}

If Chinese medicine wants to enter the overseas market, the following personnel are required: (1) familiar with the access conditions and relevant laws and regulations of Chinese medicine products entering the international market; (2) equipped with a solid professional knowledge of Chinese medicine (cultivation, processing,research and development, management of traditional Chinese medicine etc.) at the same time, have a good the communicative competence of foreign language; (3) Chinese medicine marketing talents understanding of the related Chinese national culture. Therefore, it is necessary for Chinese medicine colleges and universities to combine the training of traditional Chinese medicine skills with foreign language skills, to constantly optimize the curriculum and improve the level of output talents.

\section{Use various teaching methods to improve students' communicative ability in foreign language}

"To be good at work, and to be good at it", to use foreign language skillfully to communicate and communicate is the first condition for Chinese medicine to go global and conform to the world. In recent decades, due to the impact of exam oriented education and "cramming" teaching, the foreign language level of students is difficult to undertake the task of advancing traditional Chinese medicine to the international level. Therefore, teachers should use "cooperative learning", "flipped classroom", "micro class" and other teaching modes to improve students' intercultural communicative competence.

In the teaching practice, the author finds that, compared with the traditional foreign language teaching, cooperative learning is more effective and can stimulate students' interest in learning and improve their foreign language level. In the implementation process of cooperative learning, teachers are facilitators, students are actors, and cooperative groups think independently, clarify ideas, share results and master knowledge around the teacher's questions.

In the traditional teaching, the teacher is the leading role of the classroom, and the students are in the state of passive acceptance of knowledge. The class atmosphere is boring, the students feel boring and dull. Moreover, few students can keep the concentration during the whole class, and the teachers can't understand the mastery degree of knowledge of each student in time, leading to the lack of classroom efficiency. In the process of "cooperative learning", the teacher sets problems suitable for student discussion according to the teaching task, and guides students to actively think and participate in the discussion of each group, timely to give guidance, to stimulate students potential, to make the student experience the joyful learning process. At the same time, in this process each student does their own duties, cooperates with one another, exchanges equally, learns to listen, dare to speak, enhancing students' subject consciousness and group consciousness, cultivating the students' communication ability.

In the preview stage before class, teachers can provide some the questions with divergent thinking according to teaching content and make students think independently and seek the solution, or let the students collect relevant content according to personal preferences in groups, and communicate before class in the form of speeches, which not only can active classroom atmosphere, but also can make the students get some the knowledge, and enrich the teaching content. In view of the characteristics of foreign language discipline, teachers should make pointed references to guide students to do cooperative training and communication after class, and enhance the close connection between book knowledge and real life; The examination of some basic knowledge points can be carried out by group competition or group mutual evaluation, which can effectively combine the test and the ability training. The implementation of "cooperative learning" in class is like this: "clear questions - group cooperation - teacher guidance -" drawing conclusions". Students in the second stage will use their own knowledge reserves to actively exchange and discuss. The students will inspire each other and cultivate students' sense of cooperation. At the same time, it also makes up for the lack of teachers in the same classroom to grasp the learning status of each student.

"Cooperative learning" benefits a lot in improving students' participation, enhancing their 
cooperation consciousness, and experiencing enjoyable learning, but not to say that it is omnipotent. It should be "teaching without fixed method", adopts diversified and personalized cooperation to improve the enthusiasm of students in foreign language teaching, guide the students reading, observing and thinking independently, guide students to carry on the demonstration and discussion, to develop scientific learning methods to improve students' English level.

\section{Optimize the curriculum system, and strengthen the students' ability of sustainable development}

The curriculum provision system emphasizing the depth of the specialty, ignoring the breadth of knowledge, with too many required courses and too few elective courses makes the students a narrow range of knowledge knowledge and their not wide horizons, and then it is struggling to promote the internationalization of traditional Chinese medicine.

The Chinese medicine is unique in China, with a strong oriental culture color, and its scientific connotation has not been widely recognized and accepted by the international community, which causes that Chinese medicine had to face a lot of policy and technical barriers towards to the international stage and has become the insurmountable gap in the overseas dissemination and development of Chinese medicine. Therefore, the curriculum provision in Chinese medicine colleges and universities, based on focus on basic knowledge, basic theory and practice skills of Chinese medicine, further refines the professional characteristics of Chinese medicine , but also adds the construction of international economy, foreign culture, local customs and other international education courses, enhances the level of education internationalization, it is necessary to carry out special further description of the world's major traditional medical history and present situation, the world access regulations on Chinese medicine access, to enable students to have a fully inclusive and equitable conservation. This is a way to cultivate talents with international vision and high quality of Chinese medicine.

The theoretical system of traditional Chinese medicine handed down thousands of years ago is not only obscure to foreigners, but also differs from western medicine in its clinical diagnostic techniques and standards, and quality inspection standards. Therefore, China traditional medicine can not rest on its laurels, only the use of advanced theories and methods of modern biology, chemistry, physics and other disciplines to demonstrate and innovate, it can catch up with the world science and technology level and open the door to the world.

Three, strengthen basic knowledge of traditional Chinese medicine learning of foreign language teachers, and improve the internationalization level of Chinese medicine teachers

In the process of cultivating international talents of Chinese medicine, the most important difficulty to overcome is that professional foreign language teachers are not proficient in traditional Chinese medicine, and the internationalization level of Chinese medicine teachers is not high. In this case, in addition to the introduction of bilingual teachers, it can also make foreign language teachers and professional teachers form a "mutual object", to achieve common growth through autonomous learning, walking into the classroom and other ways .

Schools and colleges should vigorously support traditional Chinese medicine teachers to receive foreign language training, and encourage them to study abroad, participate in academic exchanges abroad, in order to improve the ability of professional teachers to use foreign language to teach Chinese medicine knowledge. Moreover, it aims to guide foreign language teachers to participate in the training course of traditional Chinese medicine, and lay the foundation for the cultivation of international talents of traditional Chinese medicine through cross-disciplinary and interdisciplinary learning.

Four, broaden the channels of international cooperation and exchange

Implementing the strategy of "going out" and "inviting in", strengthening communication and communication with foreign countries are important ways to promote the internationalization of traditional Chinese medicine.

The so-called "going out" means that the professional talents of Chinese medicine actively participate in overseas research and international conferences, and timely disseminate traditional Chinese medicine ideas to other countries; To carry out some high-level exchanges and cooperation 
with foreign institutions and universities; By setting up study classes or training classes of different levels in overseas, they should positively popularize traditional ideology and culture,service and products of traditional Chinese medicine to other countries, and improve the international recognition of traditional Chinese medicine, etc.

"Inviting in" refers to that we not only invite experts t the national traditional medicine professional from other countries, and learn from excellent experience of other countries in the development of traditional medicine, but also invite in foreign patients to clinical reception and cure within the scope permitted under applicable law by clinical personnel, and let them feel the magic and charm of traditional Chinese medicine.

Under the strategy background of the implementation of "The Belt and Road" in our country, with the change of the concept of health and the medical model, Chinese traditional medicine ushered in the unprecedented development opportunity, so cultivating internationalized talents of Chinese medicine is of great significance on promoting the development of Chinese traditional medicine in countries along the The Belt and Road. Therefore, the optimization of personnel training mode, and the cultivation of internationalized talents with solid professional knowledge, proficient basic skills, the international practice and relevant laws and regulations, an international vision and innovation consciousness and the ability of cross-cultural communication to make Chinese traditional medicine to the world stage is the problem we need to solve. Of course, the internationalization of traditional Chinese medicine will not be smooth sailing. We have a long way to go, and should actively take measures to solve the encountered problems.

\section{References}

[1].Xu Wanqiang, Chen Bing. 'Talent demand structure Analysis of internationalization of traditional Chinese medicine industry'. "Science \& Technology Progress and Policy". 2004(21-6) . [2]. Niu Suzhen,Yan Jufeng, Sun Shijiang. 'A preliminary study on talents training with higher education internationalization'. "Journal of Hebei Traditional Chinese Medicine and Pharmacology”. 2005(3).

[3]. Gao Baotong. 'Discuss the countermeasures of strengthening international communication and cooperation in colleges and universities'. "Journal of Beijing Electric Power College, Social Science Edition”. 2012(29).

[4]. Xie Qun. 'Application of cooperative learning in the cultivation of internationalized talents of traditional Chinese Medicine’. “Business” . 2014(41).

[5]. 'Chinese medicine diplomacy: how to go the international route'. “Guangming daily”. January 4, 2016

[6]. Wang Liyuan, Wan Hongjiao, Ma Guangqiang. 'A preliminary study to strengthen the cultivation path of international talent of traditional Chinese medicine'. "Journal of Traditional Chinese Medicine Management”. 2016,24(22). 